\title{
A survey of physician practices on the inpatient medical stabilization of patients with avoidant/restrictive food intake disorder
}

\author{
Carly E. Guss ${ }^{*}$ (D), Tracy K. Richmond and Sara Forman
}

\begin{abstract}
Background: Avoidant/restrictive food intake disorder (ARFID) was added to the Diagnostic and Statistical Manual of Mental Disorders Fifth Edition in 2013. ARFID can result in impaired growth and significant nutritional deficiency; individuals with ARFID may be so nutritionally compromised that they require medical stabilization in a hospital. Prior to the new diagnostic criteria, it is unclear how patients now diagnosed with ARFID may have been medically stabilized when hospitalized. Our study aim was to assess the inpatient medical management of adolescents with ARFID.
\end{abstract}

Methods: United States-based physician members of the Society for Adolescent Health and Medicine's Eating Disorder Special Interest Group's listserv or the National Eating Disorders Quality Improvement Collaborative were invited to participate in an anonymous survey regarding their practices of care for hospitalized patients with ARFID.

Results: Thirty-seven (44.6\%) of 83 physicians completed the survey; $73.0 \%(n=27)$ of respondents medically admitted patients with ARFID. Half of respondents who admitted did not use any protocol for refeeding; 55\% of those with a protocol used an anorexia nervosa treatment protocol. Solid food and nasogastric feeds were most commonly used for nutritional rehabilitation. Few typically prescribed medications in the hospital during medical stabilization.

Conclusions: There is considerable variability of practice in the treatment of hospitalized patients with ARFID. An important next step is to test the efficacy of protocols for anorexia nervosa in treating ARFID patients.

\section{Plain ENGLISH summary}

The diagnosis of Avoidant/Restrictive food intake disorder (ARFID) was added to the Diagnostic and Statistical Manual of Mental Disorders Fifth Edition in 2013. It has been used in order to describe patients with poor nutritional intake leading to weight loss and/or growth failure but without poor body image. These patients may need to be hospitalized, and there is currently very little research on how treatment of ARFID in the hospital may be different than patients with anorexia. This study surveyed physicians in the United States who care for patients with ARFID who require medical

\footnotetext{
* Correspondence: carly.guss@childrens.harvard.edu

Division of Adolescent/Young Adult Medicine, Boston Children's Hospital, Department of Pediatrics, Harvard Medical School, 300 Longwood Avenue, Boston, MA 02115, USA
}

hospitalization. Respondents to our survey often used a multidisciplinary team to care for patients with ARFID and that nasogastric feeding tubes are often used. Moreover, the findings demonstrated that there is no standardized way to care for patients with ARFID, and many providers are relying on anorexia nervosa protocols. This variability in treatment demonstrates that further studies are needed to determine what protocols may be best used in this patient population.

\section{Background}

Diagnosis and treatment of patients with eating disorders is evolving as evidenced by recent changes in eating disorder classifications in the Diagnostic and Statistical Manual of Mental Disorders Fifth Edition (DSM-5). Avoidant/restrictive food intake disorder (ARFID) is one

(c) The Author(s). 2018 Open Access This article is distributed under the terms of the Creative Commons Attribution 4.0 International License (http://creativecommons.org/licenses/by/4.0/), which permits unrestricted use, distribution, and 
of several new diagnoses added to the DSM-5 in 2013 [1]. ARFID emerged due to lack of an encompassing diagnosis to describe patients with inadequate nutritional intake but absent body dysmorphia [2]. ARFID is not a diagnosis limited to youth; ARFID may also be diagnosed in the adult population [3]. The publication of the DSM-5 and with it the definition of ARFID as a diagnosis has made the study of patients with ARFID easier as prior to the DSM-5 they may have been given several different diagnoses. Regardless of the etiology of ARFID, the diagnosis states that there are medical or psychosocial complications that require intervention [4]. While estimates of ARFID's prevalence vary, one study of patients with eating disorders across several institutions found that $14 \%$ met the DSM- 5 criteria for ARFID [5]. As ARFID can result in impaired growth and significant nutritional deficiency, these patients may require medical stabilization. Hospitalized patients with ARFID tend to be younger and require longer hospital stays than patients with other eating disorders leading to hospitalization [6, 7]. Prior to the new diagnostic criteria, it is unclear how patients now diagnosed with ARFID may have been medically stabilized when hospitalized. A recent retrospective chart review of patients assessed for an eating disorder found that more than half (57\%) of patients diagnosed with ARFID had an inpatient hospitalization [8]. There are not published criteria for the admission of ARFID, which means that providers may rely on established AN criteria such as bradycardia, orthostatic hypotension, electrolyte abnormalities, and low weight $[5,6,9,10]$. Descriptive studies cite reasons for hospitalization with a diagnosis of ARFID, although these are not necessarily criteria. For example, weight below $80 \%$ of goal, loss of over $20 \%$ of weight, failure of outpatient treatment, and bradycardia [8].

While methods for refeeding medically unstable patients with AN are described in clinical practice guidelines $[9,11,12]$, there is a paucity of research published on inpatient medical treatment of patients with ARFID. The aim of this preliminary study was to determine the current protocols and practices used for inpatient medical stabilization of patients with ARFID in the United States.

\section{Methods}

United States-based physician members of the Society for Adolescent Health and Medicine's Eating Disorder Special Interest Group's listserv or the National Eating Disorders Quality Improvement Collaborative [13] were invited to participate on three separate occasions via email with a link to the survey. If members were a part of both listservs, they received a single invitation. Respondents who did not admit patients with ARFID for nutritional rehabilitation in a hospital setting completed only the demographics portion of the survey. Participants were able to skip questions, so results have varying response rates. The anonymous online survey was based on our prior work assessing variability in inpatient management of patients with AN [14] and was exempt by the Boston Children's Hospital Institutional Review Board due to the fact that it was an anonymous survey of clinicians. Study data were collected and managed by REDCap (Nashville, TN).

\section{Results}

Thirty-seven of 83 eligible physicians completed the survey for a response rate of $44.6 \%$. Based on response to a single survey question, all respondents reported that they were familiar with the diagnosis of ARFID. Of those who responded, 27 (73.0\%) admitted patients with ARFID for nutritional rehabilitation. Providers who admitted patients with ARFID tended to be based in an academic medicine site and have specialization in Adolescent Medicine (Table 1).

The majority of providers admitted patients with ARFID to a mixed pediatric and adolescent medical unit (Table 2). Most respondents who cared for patients with ARFID in an inpatient setting reported that their teams included mental health providers and a medical provider. The most common adjunctive therapies available during a medical admission were group therapy and nutritional education.

With regards to providing nutritional rehabilitation to patients, only half of respondents $(n=11 / 22)$ reported having a standardized protocol (Table 2). Of those who did have a standard protocol, more than half of them $(n=6 / 11)$ used the same protocol for patients with ARFID and AN. Therefore, only $22.7 \%$ of respondents $(n=5 / 22)$ report having a non-AN refeeding protocol used for their patients with ARFID. "Regular food" was the most common form of nutrition used for nutritional rehabilitation among all providers. Feeding via nasogastric tubes was also commonly reported (50\%) and was provided as the initial feeding regimen, a nocturnal supplement, or in some other manner. Only $25.9 \%(n=7 / 27)$ providers indicated that medications were typically prescribed during admission. Of those that did prescribe, all respondents used selective serotonin reuptake inhibitors and two-thirds additionally prescribed atypical anti-psychotics.

Seven respondents replied to the question, "Is there anything else you want to share about your management of ARFID patients or your refeeding protocol (if you have one)?" The main themes from free text responses were that ARFID needs to be treated differently than $\mathrm{AN}$ and that use of a multidisciplinary approach with additional services such as behavior modification/exposure therapy is important. For example, on respondent 
Table 1 Demographic characteristics of physician respondents

\begin{tabular}{|c|c|c|}
\hline Characteristic & $\begin{array}{l}\text { All } \\
\text { Respondents } \\
n=37 \\
n(\%)\end{array}$ & $\begin{array}{l}\text { Respondents who } \\
\text { Admit ARFID Patients } \\
\text { for Medical Stabilization } \\
n=27 \\
n(\%)\end{array}$ \\
\hline \multicolumn{3}{|l|}{ Sex } \\
\hline Male & $5(13.5)$ & $4(14.8)$ \\
\hline Female & $25(67.6)$ & $16(59.3)$ \\
\hline No response & $7(18.9)$ & $7(25.9)$ \\
\hline \multicolumn{3}{|l|}{ Residency Training } \\
\hline Pediatrics & $25(67.6)$ & $18(66.7)$ \\
\hline Medicine/Pediatrics & $2(5.4)$ & $1(3.7)$ \\
\hline No response & $10(27.0)$ & $8(29.6)$ \\
\hline \multicolumn{3}{|c|}{ Adolescent Medicine Fellowship } \\
\hline Yes & $27(73.0)$ & $19(70.3)$ \\
\hline \multicolumn{3}{|c|}{ Years in practice as Attending Physician } \\
\hline$<10$ & $9(24.3)$ & $6(22.2)$ \\
\hline $10-20$ & $6(16.2)$ & $3(11.1)$ \\
\hline$>20$ & $14(37.8)$ & $10(37.0)$ \\
\hline No response & $8(21.6)$ & $8(29.6)$ \\
\hline \multicolumn{3}{|l|}{ Practice setting } \\
\hline Academic & $21(56.8)$ & $17(63.0)$ \\
\hline Group private practice & $4(10.8)$ & $0(0)$ \\
\hline $\begin{array}{l}\text { Health maintenance } \\
\text { organization }\end{array}$ & $2(5.4)$ & $0(0)$ \\
\hline Solo private practice & $1(2.7)$ & $1(3.7)$ \\
\hline Community hospital & $1(2.7)$ & $0(0)$ \\
\hline No response & $8(21.6)$ & $8(29.6)$ \\
\hline \multicolumn{3}{|l|}{ Practice location } \\
\hline Northeast & $11(29.7)$ & $6(22.2)$ \\
\hline West & $10(27.0)$ & $7(25.9)$ \\
\hline South & $5(13.6)$ & $3(11.1)$ \\
\hline Midwest & $3(8.1)$ & $3(11.1)$ \\
\hline No response & $8(23.6)$ & $8(29.6)$ \\
\hline
\end{tabular}

said: "Patients with ARFID [are] generally only hospitalized if $<75 \% \mathrm{MBW}$ or medically unstable. Treatment is focused on exposure, [occupational therapy] more involved than with other ED patients, often will have a behavior modification program put in place by OT and psych." Another respondent said, "patients with ARFID are treated on our specialized medical ED unit with strong multidisciplinary presence. The framework is our structured [Family Based Treatment]-based ED program but the treatment is very much individualized for these patients depending on their symptoms and presentation." Another respondent noted that they "are struggling with trying to figure out how to provide services for [both patients with ARFID and AN] in our partial hospitalization program... we treat [patients with ARFID] like other AN patients who are admitted but will use the foods they are comfortable with rather than feeding them everything like the AN patients."

\section{Discussion}

This preliminary study is the first of its kind to examine inpatient medical provider management practices for medical stabilization of patients with ARFID. We found that providers were rarely using standardized refeeding protocols aimed at ARFID. Although patients with ARFID differ significantly from patients with AN [1], half of medical providers using protocols relied on AN protocols. Providers' concerns in open text responses reflect the need for research to clarify the efficacy of various treatments. This reflects how new ARFID is as diagnosis and subsequent lack of evidence for effective treatment. Moreover, few providers were prescribing medications to treat patients. There currently are not evidence-based pharmacologic treatments for ARFID [15]. In this survey providers who prescribed medications more commonly used SSRIs, although a recent case report notes that an adolescent patient was successfully treated for ARFID with buspirone [16], demonstrating that more research to optimize pharmacological interventions is needed. A commonality among providers was the incorporation of a multidisciplinary team, which was previously found to be of benefit [17]. Additionally, nutritional rehabilitation was frequently achieved with food and nasogastric tubes, although the efficacy of nasogastric tubes in this population is unknown. One retrospective review of outcomes of an inpatient protocol for medical stabilization of eating disorders found that patients with ARFID were significantly more likely to require nasogastric tube feeding compared to other eating disorder diagnoses [18]. These results stress the need for assessment and evaluation of the efficacy of currently used treatment modalities for patients with ARFID.

The strengths of this preliminary study include the variability in practice experience and geographic location of the respondents and the wide range of years in practice of the physicians who participated in the survey. Additionally, this was an investigation of current practices from providers who actively treat ARFID patients. There are limitations to our study. We had an overall response rate of $44.6 \%$, and of the respondents not all admitted patients with ARFID for inpatient nutritional rehabilitation. Thus, the resulting sample was small and limits further analysis of results. The sample of providers is adolescent medicine-focused so results may not reflect the management of younger children with ARFID. We believe if there is bias in our results, they would overstate the use of protocols and common practices given the source for our sample. Respondents were not asked 
Table 2 Inpatient refeeding protocol and inpatient care team ${ }^{a}$

\begin{tabular}{|c|c|}
\hline Characteristic & $n(\%)$ \\
\hline Admission location (select all that apply) & $n=26$ \\
\hline Mixed pediatric and adolescent medical unit & $14(51.9)$ \\
\hline Adolescent medical unit & $4(14.8)$ \\
\hline Adolescent psychiatric unit & $3(11.1)$ \\
\hline Medical/psychiatric unit & $3(11.1)$ \\
\hline Pediatric intensive care unit & $1(3.7)$ \\
\hline Other & $2(7.4)$ \\
\hline Specific refeeding protocol & $n=22$ \\
\hline No & $11(50.0)$ \\
\hline Yes & $11(50.0)$ \\
\hline If yes, protocol same as anorexia protocol & $6 / 11(54.0)$ \\
\hline Form of nutrition for refeeding (select all that apply) & $n=22$ \\
\hline Food & $20(90.9)$ \\
\hline Nasogastric feeds & $11(50.0)$ \\
\hline Comfort foods & $10(45.4)$ \\
\hline Liquid nutrition & $10(45.4)$ \\
\hline Intravenous fluids & $2(9.1)$ \\
\hline Total parenteral nutrition & $1(4.5)$ \\
\hline Meals observed & $n=21$ \\
\hline Yes & $18(85.7)$ \\
\hline No & $3(14.3)$ \\
\hline Patient weighed daily & $n=22$ \\
\hline No & $1(4.5)$ \\
\hline Yes & $21(95.5)$ \\
\hline When phosphorus supplements prescribed & $n=22$ \\
\hline Only if phosphorus drops & $13(59.1)$ \\
\hline On all patients & $7(31.8)$ \\
\hline Never & $1(4.5)$ \\
\hline Other & $1(4.5)$ \\
\hline Inpatient care team members (select all that apply) & $n=22$ \\
\hline Adolescent medicine & $21(95.5)$ \\
\hline Psychiatrist & $19(86.4)$ \\
\hline Psychologist & $16(72.7)$ \\
\hline Social work & $13(59.0)$ \\
\hline Family based treatment therapist & $5(22.7)$ \\
\hline Occupational therapist & $4(18.2)$ \\
\hline General pediatrics & $4(18.2)$ \\
\hline Family therapist & $3(13.6)$ \\
\hline Feeding specialist & $2(9.1)$ \\
\hline Medications are typically prescribed & $n=20$ \\
\hline No & $13(59.1)$ \\
\hline Yes & $7(35.0)$ \\
\hline
\end{tabular}

Table 2 Inpatient refeeding protocol and inpatient care team ${ }^{a}$ (Continued)

\begin{tabular}{ll}
\hline Characteristic & $n(\%)$ \\
\hline Which medications are prescribed (select all that apply) & $n=6$ \\
Selective serotonin reuptake inhibitor & $6(100.0)$ \\
Multivitamin & $4(66.7)$ \\
Atypical antipsychotic & $4(66.7)$ \\
Benzodiazepines & $4(66.7)$ \\
Cyproheptadine & $3(50.0)$ \\
Fish oil & $2(33.3)$
\end{tabular}

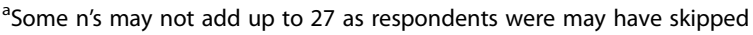
questions or were allowed to select more than one characteristic

${ }^{b}$ Respondents answered that medications are typically prescribed and then received additional questions about each medication. Answers in table reflect options of "yes, sometimes" and "yes, always"

if patients were admitted to other services, such as gastroenterology, where other specialties may treat these patients differently. However, one retrospective study of gastroenterology clinics found only $1.5 \%$ of referral patients had ARFID, so it is perhaps less likely they would be admitted to gastroenterology [19]. Additionally, more specific measures of medical treatment may not be captured by this survey and there is no further information regarding the intricacies of the protocols developed by providers. Further research should seek to describe specific information for discharge criteria for ARFID patients as well as recommended post-discharge treatment after an inpatient stay for development of future protocols. A comparison of low-weight patients with ARFID to patients with AN demonstrated similar improvements in a partial hospitalization program, suggesting that there are areas of treatment that may overlap between the two diagnoses [20]. However, it is important to have a baseline for how ARFID patients are treated in inpatient settings before developing new protocols.

\section{Conclusion}

In conclusion, the variability in the treatment approaches to the inpatient medical stabilization of patients with ARFID highlights the evidence gap regarding optimal treatment of this disorder. This may help explain why ARFID may result in longer hospital stay [21]. Additionally, as of now, there is a lack of randomized control trials to establish evidence-based treatment of ARFID, including studies to support the use of medication in either an inpatient or outpatient setting [4]. It may be that no single treatment works best for all ARFID patients, although as evidenced by this survey a multidisciplinary team is likely important to the effectiveness of treatment [21]. Development of future protocols should consider the socio-culture background and values of patients [22] as well as the differences between typical patients 
with ARFID and AN (such as younger age, prevalence of history of choking/gagging episode, and lack of body dysmorphia in those with ARFID in contrast to those with AN). An important next step is to assess the effectiveness of current protocols used in the treatment of patients with ARFID across programs.

\section{Abbreviations}

AN: Anorexia nervosa; ARFID: Avoidant/restrictive food intake disorder; DSM5: Diagnostic and Statistical Manual of Mental Disorders Fifth Edition

\section{Acknowledgements}

The authors would like to acknowledge S. Bryn Austin, ScD and S. Jean Emans, MD for their feedback and guidance.

\section{Funding}

Dr. Guss was partially supported by the HRSA/MCHB Leadership Education in Adolescent Health (LEAH) training grant T71-MC00009. The funding had no role in the design of the study and collection, analysis, and interpretation of data.

\section{Availability of data and materials}

The datasets used and/or analyzed during the current study are available from the corresponding author on reasonable request.

\section{Authors' contributions}

CG planned the study, designed the survey questions, collected the data, contributed to data analysis, and drafted and critically reviewed the manuscript. TR reviewed the survey questions, contributed to data interpretation, and critically reviewed the manuscript. SF oversaw study and survey design, contributed to data interpretation, and critically reviewed the manuscript. All authors read and approved the final manuscript.

\section{Ethics approval and consent to participate}

This study was exempt by the Boston Children's Hospital Institutional Review Board due to the fact that it was an anonymous survey of clinician.

\section{Consent for publication}

Not applicable.

\section{Competing interests}

The authors declare that they have no competing interests.

\section{Publisher's Note}

Springer Nature remains neutral with regard to jurisdictional claims in published maps and institutional affiliations.

Received: 4 May 2018 Accepted: 16 August 2018

Published online: 26 September 2018

\section{References}

1. American Psychiatric Association. Diagnostic and statistical manual of mental disorders: DSM-5. Arlington, VA: American Psychiatric Association; 2013.

2. Norris ML, Spettigue WJ, Katzman DK. Update on eating disorders: current perspectives on avoidant/restrictive food intake disorder in children and youth. Neuropsychiatr Dis Treat. 2016;12:213-8. https://doi.org/10.2147/NDT. S82538

3. Fitzgerald M, Frankum B. Food avoidance and restriction in adults: a crosssectional pilot study comparing patients from an immunology clinic to a general practice. J Eat Disord. 2017;5:30. https://doi.org/10.1186/s40337-0170160-4.

4. Thomas JJ, Lawson EA, Micali N, Misra M, Deckersbach T, Eddy KT. Avoidant/ restrictive food intake disorder: a three-dimensional model of neurobiology with implications for etiology and treatment. Curr Psychiatry Rep. 2017;19:54. https://doi.org/10.1007/s11920-017-0795-5.

5. Fisher MM, Rosen DS, Ornstein RM, Mammel KA, Katzman DK, Rome ES, et al. Characteristics of avoidant/restrictive food intake disorder in children and adolescents: a "new disorder" in DSM-5. J Adolesc Health. 2014:55:49-52. https://doi.org/10.1016/j.jadohealth.2013.11.013.
6. Strandjord SE, Sieke EH, Richmond M, Rome ES. Avoidant/restrictive food intake disorder: illness and hospital course in patients hospitalized for nutritional insufficiency. J Adolesc Health. 2015;57:673-8. https://doi.org/10. 1016/j.jadohealth.2015.08.003.

7. Nicely TA, Lane-Loney S, Masciulli E, Hollenbeak CS, Ornstein RM. Prevalence and characteristics of avoidant/restrictive food intake disorder in a cohort of young patients in day treatment for eating disorders. J Eat Disord. 2014;2:21. https://doi.org/10.1186/s40337-014-0021-3.

8. Cooney M, Lieberman M, Guimond T, Katzman DK. Clinical and psychological features of children and adolescents diagnosed with avoidant/restrictive food intake disorder in a pediatric tertiary care eating disorder program: a descriptive study. J Eat Disord. 2018;6:7. https://doi.org/ 10.1186/s40337-018-0193-3.

9. Golden NH, Katzman DK, Sawyer SM, Ornstein RM, Rome ES, Garber AK, et al. Position Paper of the Society for Adolescent Health and Medicine: medical management of restrictive eating disorders in adolescents and young adults. J Adolesc Health. 2015;56:121-5. https://doi.org/10.1016/j. jadohealth.2014.10.259.

10. Schwartz BI, Mansbach JM, Marion JG, Katzman DK, Forman SF. Variations in admission practices for adolescents with anorexia nervosa: a North American sample. J Adolesc Health. 2008;43:425-31. https://doi.org/10.1016/ j.jadohealth.2008.04.010.

11. Garber AK, Sawyer SM, Golden NH, Guarda AS, Katzman DK, Kohn MR, et al. A systematic review of approaches to refeeding in patients with anorexia nervosa. Int J Eat Disord. 2015; https://doi.org/10.1002/eat.22482.

12. Campbell K, Peebles R. Eating disorders in children and adolescents: state of the art review. Pediatrics. 2014;134:582-92. https://doi.org/10.1542/peds. 2014-0194.

13. Forman SF, Grodin LF, Graham DA, Sylvester CJ, Rosen DS, Kapphahn CJ, et al. An eleven site National Quality Improvement Evaluation of adolescent medicine-based eating disorder programs: predictors of weight outcomes at one year and risk adjustment analyses. J Adolesc Health. 2011;49:594-600.

14. Schwartz BI, Mansbach JM, Marion JG, Katzman DK, Forman SF, Variations in admission practices for adolescents with anorexia nervosa: a north American sample. J Adolesc Health. 2008:43:425-31. https://doi.org/10.1016/ j.jadohealth.2008.04.010.

15. Kelly NR, Shank LM, Bakalar JL, Tanofsky-Kraff M. Pediatric feeding and eating disorders: current state of diagnosis and treatment. Curr Psychiatry Rep. 2014;16:446. https://doi.org/10.1007/s11920-014-0446-z.

16. Okereke NK. Buspirone Treatment of Anxiety in an Adolescent Female with Avoidant/Restrictive Food Intake Disorder. J Child Adolesc Psychopharmacol: 2018:cap.2018.0005. https://doi.org/10.1089/cap.2018.0005.

17. Katzman DK, Stevens K, Norris M. Redefining feeding and eating disorders: what is avoidant/restrictive food intake disorder? Paediatr Child Health. 2014;19:445-6. https://www.ncbi.nlm.nih.gov/pmc/articles/PMC4220532/. Accessed 1 Dec 2015

18. Peebles R, Lesser A, Park CC, Heckert K, Timko CA, Lantzouni E, et al. Outcomes of an inpatient medical nutritional rehabilitation protocol in children and adolescents with eating disorders. J Eat Disord. 2017:5:7. https://doi.org/10.1186/s40337-017-0134-6.

19. Eddy KT, Thomas JJ, Hastings E, Edkins K, Lamont E, Nevins CM, et al. Prevalence of DSM-5 avoidant/restrictive food intake disorder in a pediatric gastroenterology healthcare network. Int J Eat Disord. 2015;48:464-70. https://doi.org/10.1002/eat.22350.

20. Bryson AE, Scipioni AM, Essayli JH, Mahoney JR, Ornstein RM. Outcomes of low-weight patients with avoidant/restrictive food intake disorder and anorexia nervosa at long-term follow-up after treatment in a partial hospitalization program for eating disorders. Int J Eat Disord. 2018;51:470-4. https://doi.org/10.1002/eat.22853.

21. Pitt PD, Middleman AB. A Focus on Behavior Management of Avoidant/ Restrictive Food Intake Disorder (ARFID): A Case Series. Clin Pediatr (Phila). 2017:000992281772115. https://doi.org/10.1177/0009922817721158.

22. Schermbrucker J, Kimber M, Johnson N, Kearney S, Couturier J. Avoidant/restrictive food intake disorder in an 11-year old south American boy: medical and cultural challenges. J Can Acad Child Adolesc Psychiatry. 2017;26:110-3. https://www.ncbi.n/m.nih.gov/pmc/ articles/PMC5510940/. Accessed 20 July 2018. 